\title{
La difusión de las campañas de prevención del VIH en la prensa escrita española
}

\author{
Nuria Luque Martín \\ Manuela López Doblas \\ Escuela Andaluza de Salud Pública \\ (Sevilla, España) \\ Joan Carles March Cerdà \\ Alina Danet \\ Escuela Andaluza de Salud Pública \\ CIBER Epidemiología y Salud Pública \\ (Sevilla, España)
}

\section{Palabras clave}

$\mathrm{VIH}$

campañas de prevención medios de comunicación

\section{Resumen}

El objetivo de esta investigación fue conocer la cobertura mediática en la prensa general escrita de las campañas de prevención del VIH realizadas por el Sistema Público Nacional de Salud (SPNS). Se realizó un estudio exploratorio de análisis de prensa, con metodología cuantitativa-cualitativa, entre septiembre y diciembre de 2011. El estudio incluyó 17 campañas de prevención del VIH realizadas en el marco del SPNS, entre 2004 y 2010. Los medios de comunicación seleccionados fueron cinco periódicos nacionales: El País, El Mundo, ABC, La Vanguardia y El Periódico. Tras realizar una descripción cuantitativa de los materiales de prensa, el análisis cualitativo se ha estructurado en base al modelo propuesto por Gioda y Llobet (1995): código lingüístico, paralingüístico e icónico. El estudio muestra que la cobertura mediática de las campañas seleccionadas fue escasa, recibiendo mayor atención las campañas dirigidas a la población general y con mensajes de concienciación social. El género más frecuente es la noticia y el registro, el informativo. Las fuentes más representadas son de tipo institucional, mientras que las opiniones emergentes de la sociedad civil apenas se visibilizan. En conclusión, existe un patrón similar en la difusión de las diferentes campañas de prevención del VIH, con una escasa cobertura mediática. Sería necesario intensificar la investigación sobre nuevas estrategias de difusión, que garanticen una mayor cobertura de las campañas. 


\section{The coverage of HIV prevention campaigns in the Spanish press}

\section{Keywords \\ HIV \\ prevention campaigns \\ mass-media}

\begin{abstract}
The object of this study is to learn about the media coverage of the general written press regarding HIV prevention campaigns carried out by the Spanish Public Healthcare System. An exploratory analysis of the relevant press was undertaken between September and December 2011, using quantitative and qualitative methodologies. The study included 17 HIV prevention campaigns implemented by the Spanish Public Healthcare System between 2004 and 2010. Five national newspapers comprised the media outlets chosen for the study, including: El País, El Mundo, ABC, La Vanguardia and El Periódico. Having carried out a quantitative description of press materials, the qualitative study was structured according to the model proposed by Gioda and Llobet (1995), using linguistic, paralinguistic and iconic codes. The study shows that press coverage of the campaigns was limited, with more attention being given to the campaigns focused on the general public and on social awareness messages. The most common genre is the news story and the tone is usually informative. While institutional sources are the most frequently represented, the opinions of civil society are hardly visible. In conclusion, there exists a similar pattern among HIV prevention campaigns in terms of dissemination, with limited media coverage. Further analysis regarding media distribution strategies is needed so as to guarantee wider media coverage of these campaigns.
\end{abstract}

\section{Cómo citar el artículo}

Luque Martín, N.; López Doblas, M.; March Cerdà, J. C.; Danet, A. (2014). La difusión de las campañas de prevención del VIH en la prensa escrita española. Revista de Comunicación y Salud, Vol. 4, pp. 5-17. DOI: http://doi.org/10.35669/revistadecomunicacionysalud.2014.4.5-17 


\section{Introducción}

Confirmando el rol de la prensa, centrado en encuadrar los problemas sociales y sanitarios (Paricio-Esteban, Rodríguez-Luque, Rabadán-Zaragoza, 2012) e influir en la percepción de las audiencias (Humanes, 2003), los medios de comunicación se han constituido como un agente social relevante en la difusión de campañas sanitarias. Siguiendo a Day (2001), la información difundida en la prensa puede conllevar cambios de actitud y, en base a una motivación efectiva, puede incidir en los conductas.

En relación a la prevención del $\mathrm{VIH}$, a partir de los ochenta, desde las ciencias sociales y de la comunicación se ha resaltado el papel de la prensa en crear la conciencia social sobre el riesgo de transmisión de la enfermedad (Lehmann y Töppich, 2009) o en generar cambios de actitudes y comportamientos (Bekalu y Eggermont, 2012), a nivel individual y social (Abroms y Maibach, 2008). La intervención preventiva a través de campañas mediáticas tiene resultados efectivos sobre la actitud hacia la prueba de detección (Vidanapathirana et al., 2005) o el uso del condón (Agha, 2003; Moore, 2009), aunque el impacto en el comportamiento suele ser mayor cuando el objetivo de la campaña es incentivar una nueva conducta y no eliminar o prevenir una conducta perjudicial (Snyder y Hamilton, 2002).

En España, el interés por la difusión de la información sanitaria sobre el VIH, iniciada a finales de los ochenta (Feijoo Agesta, 1989), se ha ido intensificando en la década de los noventa (Blanco et al, 1995; Martínez Nicolás, 1995; Tuñón, 1994). Una revisión bibliográfica reciente (Terrón Blanco, 2011) sobre estudios realizados en España (Martín Hernández, 2009; Garabato González, 2003), revela un descenso paulatino de la oferta informativa sobre $\mathrm{VIH}$, además señala que ésta se sirve de un registro lingüístico informativo, con un uso impreciso del lenguaje frecuente. Las fuentes de información más prevalentes son las institucionales.

Partiendo de que la difusión de la prevención del VIH es un proceso comunicativo complejo, en el que la prensa enfoca y modula los mensajes de las campañas, el objetivo general del estudio es conocer la cobertura mediática de las campañas de prevención del VIH realizadas por el Sistema Público Nacional de Salud (SPNS) en la prensa general escrita.

\section{Objetivos}

Se realizó un estudio cuantitativo-cualitativo (septiembre-diciembre 2011) sobre la difusión periodística de las campañas de prevención del VIH realizadas en el marco del SPNS.

El estudio incluyó las campañas elaboradas entre 2004 y 2010, con distintas poblaciones diana (población general, población inmigrante y hombres que tienen sexo con hombres -HSH-) y objetivos. La tabla 1 recoge la información sobre las 17 campañas evaluadas, según año, eslógan, población diana y contexto de difusión. 
Tabla 1. Campañas de prevención del VIH evaluadas (Ordenadas por año)

\begin{tabular}{|c|c|c|c|}
\hline Campaña & Población diana & Tipo (contexto) & Año \\
\hline Quiérete & Población general & Día Mundial del Sida & 2010 \\
\hline ¿Hablamos? & Población inmigrante & Campaña información & 2010 \\
\hline Ponte una medalla & $\mathrm{HSH}$ & $\begin{array}{l}\text { Promoción del uso de } \\
\text { preservativo }\end{array}$ & 2010 \\
\hline $\begin{array}{l}\text { Detrás del Sida hay mucha } \\
\text { vida. Si me besas te transmitiré } \\
\text { ternura }\end{array}$ & Población general & Día Mundial del Sida & 2009 \\
\hline $\begin{array}{l}\text { Frente al VIH no bajes la } \\
\text { guardia }\end{array}$ & $\mathrm{HSH}$ & $\begin{array}{l}\text { Promoción del uso de } \\
\text { preservativo }\end{array}$ & 2009 \\
\hline No dejes que el VIH se fije en $t i$ & $\mathrm{HSH}$ & $\begin{array}{l}\text { Promoción del uso de } \\
\text { preservativo }\end{array}$ & 2009 \\
\hline Actúa & Población general & Día Mundial del Sida & 2008 \\
\hline $\begin{array}{l}\text { La prueba es la respuesta. } \\
\text { Háztela }\end{array}$ & Población general & $\begin{array}{l}\text { Promoción de la prueba } \\
\text { de VIH }\end{array}$ & 2008 \\
\hline Por ti, por mí, hazte la prueba & $\mathrm{HSH}$ & $\begin{array}{l}\text { Promoción de la prueba } \\
\text { de VIH }\end{array}$ & 2008 \\
\hline $\begin{array}{l}\text { Son más los lazos que nos } \\
\text { unen a ti que los que nos } \\
\text { separan }\end{array}$ & Población general & Día Mundial del Sida & 2007 \\
\hline $\begin{array}{l}\text { El Sida no entiende de culturas, } \\
\text { fronteras o colores }\end{array}$ & Población inmigrante & $\begin{array}{l}\text { Promoción del uso de } \\
\text { preservativo }\end{array}$ & 2007 \\
\hline $\begin{array}{l}\text { Entre nosotros: usa } \\
\text { preservativo }\end{array}$ & $\mathrm{HSH}$ & $\begin{array}{l}\text { Promoción del uso de } \\
\text { preservativo }\end{array}$ & 2007 \\
\hline $\begin{array}{l}\text { El mundo aún necesita } \\
\text { kilómetros de compromiso }\end{array}$ & Población general & Día Mundial del Sida & 2006 \\
\hline ¿Sabes quién actúa? & Población joven & $\begin{array}{l}\text { Prevención en población } \\
\text { joven }\end{array}$ & 2006 \\
\hline $\begin{array}{l}\text { Nosotros disfrutamos seguros. } \\
\text { Tú decides }\end{array}$ & $\mathrm{HSH}$ & $\begin{array}{l}\text { Promoción del uso de } \\
\text { preservativo }\end{array}$ & 2006 \\
\hline Detén el sida. Haz la promesa & Población general & Día Mundial del Sida & 2005 \\
\hline Por ti, por todos, úsalo & Población general & $\begin{array}{l}\text { Promoción del uso de } \\
\text { preservativo }\end{array}$ & 2004 \\
\hline
\end{tabular}

Los medios de comunicación seleccionados son las versiones digitales de los cinco periódicos nacionales de mayor tirada en España (AIMC, 2011): El País, El Mundo, $A B C$, La Vanguardia y El Periódico. Las búsquedas se han desarrollado en varias fases: búsqueda general (descriptores "sida+VIH" y "campaña+sida+VIH") y búsquedas específicas por campaña y año de difusión (descriptores "campaña+sida+VIH+eslógan literal"). 
La primera parte del análisis ha incluido una descripción cuantitativa de los materiales. El estudio cualitativo se ha basado en el análisis de contenido de cada noticia, en función de tres tipos de códigos (Gioda y Llobet, 1995): lingüístico, paralingüístico e icónico. La Tabla 2 recoge las variables de análisis en un esquema final de análisis.

Tabla 2. Variables del análisis de contenido

\begin{tabular}{|l|}
\hline Código lingüístico \\
\hline Titular \\
\hline Género \\
\hline Contenidos/ideas principales \\
\hline Información sobre la campaña \\
\hline Valoración de la campaña \\
\hline Código paralingüístico \\
\hline Fuentes/ portavoces \\
\hline Extensión \\
(Amplia = más de una página; Media $=$ \\
entre 1 pág y $1 / 2$ página; baja = menos \\
de $1 / 2$ página) \\
\hline Sección \\
\hline Código icónico \\
\hline Imagen \\
\hline
\end{tabular}

\section{Resultados}

El estudio refleja la reducida difusión de las campañas de prevención del VIH en los medios escritos (Tabla 3).

Tabla 3. $\mathrm{N}^{\circ}$ de noticias y período de difusión en las fuentes periodísticas estudiadas

\begin{tabular}{|l|l|l|l|l|l|l|}
\hline \multicolumn{1}{|c|}{$\begin{array}{c}\text { Campaña } \\
\text { (Período de difusión) }\end{array}$} & EI País & $\begin{array}{c}\text { EI } \\
\text { Mundo }\end{array}$ & ABC & $\begin{array}{c}\text { La } \\
\text { Vanguardia }\end{array}$ & $\begin{array}{c}\text { EI } \\
\text { Periódico }\end{array}$ & Total \\
\hline Quiérete (29 nov-1 dic 2010) & 1 & 3 & 3 & - & - & 7 \\
\hline ¿Hablamos? (26 nov 2010) & - & 1 & 1 & 1 & 1 & 4 \\
\hline $\begin{array}{l}\text { Ponte una medalla (23 jun- 4 } \\
\text { jul 2010) }\end{array}$ & - & 1 & 2 & - & 1 & 4 \\
\hline $\begin{array}{l}\text { Detrás del Sida hay mucha } \\
\text { vida. Si me besas te } \\
\text { transmitiré ternura (29 nov- 2 } \\
\text { dic 2009) }\end{array}$ & - & 2 & 4 & 1 & - & 7 \\
\hline $\begin{array}{l}\text { Frente al VIH no bajes la } \\
\text { guardia (1-5 jul 2009) }\end{array}$ & 1 & 1 & 1 & - & - & 3 \\
\hline
\end{tabular}




\begin{tabular}{|c|c|c|c|c|c|c|}
\hline $\begin{array}{l}\text { No dejes que el VIH se fije en } \\
\text { ti (9-10 dic de 2009) }\end{array}$ & 1 & 1 & 2 & - & - & 4 \\
\hline Actúa (27 nov- 2 dic 2008 ) & 1 & - & 3 & - & 1 & 5 \\
\hline $\begin{array}{l}\text { La prueba es la respuesta. } \\
\text { Háztela (2008) }\end{array}$ & - & - & - & - & - & - \\
\hline $\begin{array}{l}\text { Por ti, por mí, hazte la prueba } \\
\text { (17-18 de dic) }\end{array}$ & 1 & 1 & - & - & 1 & 3 \\
\hline $\begin{array}{l}\text { Son más los lazos que nos } \\
\text { unen a ti que los que nos } \\
\text { separan ( } 30 \text { nov- } 1 \text { dic } 2007)\end{array}$ & 1 & 1 & 1 & - & - & 3 \\
\hline $\begin{array}{l}\text { El Sida no entiende de } \\
\text { culturas, fronteras o colores } \\
\text { (27-30 nov 2007) }\end{array}$ & - & 1 & 1 & - & 1 & 3 \\
\hline $\begin{array}{l}\text { Entre nosotros: usa } \\
\text { preservativo (3-11 dic 2007) }\end{array}$ & 1 & 1 & 1 & 1 & 1 & 4 \\
\hline $\begin{array}{l}\text { El Mundo aún necesita } \\
\text { kilómetros de compromiso } \\
\text { (1-2 diciembre 2006) }\end{array}$ & 1 & 1 & 1 & 1 & - & 4 \\
\hline $\begin{array}{l}\text { ¿Sabes quién actúa? (19 jul- } \\
10 \text { agos 2006; } 7 \text { mayo 2007) }\end{array}$ & 1 & 2 & 3 & - & - & 6 \\
\hline $\begin{array}{l}\text { Nosotros disfrutamos seguros. } \\
\text { Tú decides (7-9 abr 2006) }\end{array}$ & 1 & 2 & 1 & - & - & 4 \\
\hline $\begin{array}{l}\text { Detén el sida. Haz la promesa } \\
\text { (24 nov - } 1 \text { dic 2005) }\end{array}$ & 1 & 3 & - & - & - & 4 \\
\hline $\begin{array}{l}\text { Por ti, por todos, úsalo } \\
(29 \text { nov } 2004 \text { - } 19 \text { ene 2005) }\end{array}$ & 3 & 1 & 1 & 1 & 1 & 7 \\
\hline Total de campañas & 14 & 22 & 25 & 5 & 7 & 73 \\
\hline
\end{tabular}

El Mundo y $A B C$ concentran más noticias, mientras que La Vanguardia y El Periódico no hacen referencia en absoluto a 8 de las 17 campañas analizadas. Las campañas más difundidas se dirigen a la población general y se incluyen en la sección Sociedad.

\subsection{Quiérete (2010) (7 Noticias)}

Los titulares no hacen referencia al nombre de la campaña, pero las noticias aportan datos epidemiológicos. Pertenecen al género informativo, aportan la descripción y justificación de la campaña y visibilizan fuentes político-técnicas (Ministerio de Sanidad y autoridades regionales y locales de Islas Baleares) y científico-técnicas (Grupo de Estudio del Sida-Gesida, la Sociedad Española de Enfermedades Infecciosas y Microbiología Clínica- SEIMC y la Federación Estatal de Lesbianas, Gays, Transexuales y Bisexuales- FELGTB). Con una extensión media de una página, cuatro de las noticias incluyen el cartel de la campaña.

3.2. ¿Hablamos? (2010) (4 Noticias)

De tipo informativo/descriptivo, sin incluir el nombre de las campañas en el titular, las 
noticias presentan el formato de cómic, el multilingüismo, la población inmigrante y el sida. La fuente que se nombra es el Ministerio de Sanidad. La información incluye imágenes del cómic con una extensión media de una página.

\subsection{Ponte una medalla (2010) (4 Noticias)}

La difusión coincide con el acto de presentación por el Ministerio de Sanidad (22 de junio) y el desfile del Día del Orgullo Gay (2 julio). Pertenecen al género informativo, en general no vienen acompañadas de información gráfica y representan fuentes del sector político-técnico, del Ministerio de Sanidad y del sector social. Los titulares no incluyen el lema de la campaña, aunque sí describen su puesta en marcha, objetivos y población diana.

3.4 Detrás del Sida hay mucha vida. Si me besas te transmitiré ternura (2009) (7 Noticias)

Las noticias se centran en datos epidemiológicos mundiales y nacionales, especialmente relacionadas con la prevalencia del estigma social de las personas seropositivas. El eslogan de la campaña se recoge en cuatro titulares y la principal fuente de las noticias es el Ministerio de Sanidad. Otras fuentes político-técnicas mencionadas son: Asociación de Pacientes y Familiares Adhara, OMS, ONUSIDA, Colectivo de lesbianas, gays, transexuales y bisexuales de Madrid (COGAM). Sólo dos noticias son ilustradas, pero la extensión es amplia, con una página de media.

\subsection{Frente al VIH no bajes la guardia (2009) (3 Noticias)}

Dos de las tres noticias refieren literalmente el título de la campaña en sus titulares. La información es pormenorizada, incluyendo objetivos, públicos, recursos y acciones. El Ministerio de Sanidad es la única fuente que se menciona y las noticias incorporan el cartel de la campaña.

\subsection{No dejes que el VIH se fije en ti (2009) (4 Noticias)}

Las noticias informativas no difunden el lema de la campaña en sus titulares, aunque sí especifican la población diana. Las noticias aportan información epidemiológica sobre la prevalencia del virus, visibilizando representantes del Ministerio de Sanidad, asociaciones y ONGs (Stop Sida, FELGTB). La noticia de El Mundo aporta una valoración positiva de la campaña: "es un acierto que el mensaje se trasmita a través de las webs de contactos homosexuales" (Cati Zaragoza, representante de Stop Sida). Sin embargo, el dato publicado en El País, según el cual el $10 \%$ de los gays españoles tienen el VIH, cuestiona la eficiencia de los mensajes preventivos. Las noticias se acompañan de imágenes.

\subsection{Actúa (2008) (5 Noticias)}

Los titulares no recogen el nombre de la campaña, pero las noticias aportan información sobre actos y declaraciones en torno a la enfermedad. Se refieren el Ministerio de Sanidad y fuentes científico-sanitarias (Cruz Roja, SEIMC y FELGTB). Aparece la consideración de las diferencias con las campañas internacionales, en general más "duras" que las nacionales (El Periódico). Las noticias son de media página y aportan imágenes del ministro de sanidad. 


\subsection{La prueba es la respuesta. Háztela (2008) (0 Noticias)}

La prensa informa sobre la posibilidad de realizar la prueba de VIH/ Sida en farmacias catalanas y aporta datos epidemiológicos, pero la campaña no se refiere en ninguna noticia.

\subsection{Por ti, por mí, hazte la prueba (2008) (3 Noticias)}

Las noticias se centran en la prevalencia de la enfermedad en los colectivos de HSH. Los titulares no incluyen el lema de la campaña, pero los textos insisten en la realización de la prueba como estrategia eficaz de prevención. El Ministerio de Sanidad aparece como fuente principal, al que se suman el Centro de Control de Enfermedades. Sólo una de las noticias viene ilustrada con el cartel de la campaña.

3.10. Son más los lazos que nos unen a ti que los que nos separan (2007) (3 Noticias) Las noticias no incluyen el eslogan en el titular, pero nombran los objetivos de la campaña en el titular o en los subtítulos. Describen las estrategias de lucha contra la enfermedad, incluyen la relación de materiales editados, pero no incorporan información gráfica. El género informativo impera en todas las noticias, que representan fuentes políticotécnicas (Ministerio de Sanidad, Secretaría del Plan Nacional de Sida, Consejería de Sanidad de Castilla la Mancha).

3.11. El Sida no entiende de culturas, fronteras o colores (2007) (3 Noticias)

Las noticias visibilizan como único portavoz al Ministerio de Sanidad y aportan información descriptiva del lema, mensajes, objetivos y recursos de la campaña. De amplia extensión y reducida información gráfica (sólo se incluye una imagen en una de las noticias), las publicaciones no incluyen en su titular el nombre de la campaña.

\subsection{Entre nosotros: usa preservativo (2007) (4 Noticias)}

Los titulares de las noticias recogen la promoción del uso del preservativo entre HSH y la participación de personalidades públicas en la campaña. El lema "entre nosotros" aparece en tres de las noticias, destacando la población diana de la campaña. EI peso de la imagen es importante y la extensión de los textos es amplia. El sector representado es el político- técnico (Ministerio de Sanidad). Cuatro noticias pertenecen al género informativo y una al género interpretativo (crónica social, publicada en El Periódico), ofreciendo una valoración positiva de la campaña: "Tres hombres, casados con otros hombres -nada menos que el juez de la Audiencia Nacional, Fernando Grande-Marlaska, el presentador Jesús Vázquez y el escritor Boris Izaguirre- prestaron ayer su imagen para prevenir el VIH en hombres que tienen relaciones homosexuales".

\subsection{El mundo aún necesita kilómetros de compromiso (2006) (4 Noticias)}

Dos titulares hacen referencia directa a la campaña y un tercero incluye el eslogan en el subtítulo. El contenido principal, presentado en clave informativo-descriptiva, es el lanzamiento de la campaña, con una extensión de media página. A las fuentes políticotécnicas (Ministerio de Sanidad), se le suman representantes del sector científicosanitario (farmacias) y social (ONG Apoyo positivo).

3.14. ¿Sabes quién actúa? (2006) (6 Noticias)

Las publicaciones recogen datos sobre la campaña, sus objetivos, mensajes difundidos, 
públicos y presupuestos. El Ministerio de Sanidad es la principal fuente citada. Aunque sin información gráfica y de extensión media, un artículo de opinión y una carta al director de $A B C$ aportan la visión crítica sobre la idoneidad del mensaje. Basándose en "cifras preocupantes" sobre el aumento del uso de la píldora postcoital y de las ETS, el artículo reivindica la necesidad de un "mensaje más amplio y quizás más constructivo que el habitual en el que se apela a la responsabilidad, al desarrollo personal y a la fidelidad". La carta al director manifiesta la crítica al contenido de la campaña, considerando que se equipara el embarazo no deseado con las ETS.

\subsection{Nosotros disfrutamos seguros. Tú decides (2006) (4 Noticias)}

Dos de los titulares enfocan los datos de incidencia de la enfermedad, a través de textos extensos y acompañados con información gráfica. Los otros dos titulares se centran en la campaña, uno con un enfoque informativo y otro en el marco interpretativo (foto reportaje publicado en El Mundo). Estos textos ofrecen detalles sobre el lema, mensajes, objetivos y acciones promovidas. El foto reportaje interactivo repasa 20 campañas contra el sida y especifica que "Nosotros disfrutamos seguros" es la primera dedicada al colectivo homosexual. Las fuentes representadas son el Ministerio de Sanidad, así como la FELGTB y Ximo Cádiz.

\subsection{Detén el sida. Haz la promesa (2005) (4 Noticias)}

La campaña se relaciona con World Aids Campaign, lanzada a nivel internacional con el objetivo de promover el cumplimiento de la Declaración de Compromisos sobre el VIH/ Sida de la OMS. Los géneros son variados: opinión, interpretativo (reportaje/entrevista) e infografía interactiva. Los titulares refieren políticas y programas desarrollados por diferentes instituciones. Las fuentes pertenecen al sector político/técnico (médico y diputada de PSPV-PSOE en las Cortes Valencianas o la directora del Plan Nacional de Sida) y científico/sanitario (ONUSIDA, OMS). Tres de las noticias contienen imágenes y en general valoran positivamente la campaña, aunque con un enfoque crítico hacia los gobiernos e instituciones que no cumplen con su cometido adecuadamente.

\subsection{Por ti, por todos, úsalo (2004) (7 Noticias)}

Las seis noticias y un reportaje extenso se centran en el objetivo de la campaña, así como en el debate social creado en torno a la campaña, a raíz del posicionamiento en contra del uso del preservativo, manifestado por representantes de la Iglesia Católica (2 textos). En la polémica participan miembros del sector político-técnico, representado a través del Ministerio de Sanidad y del portavoz de la Conferencia Episcopal, y del científico-sanitario (Sociedad Española Interdisciplinar sobre el Sida, Asociación de Planificación Familiar de Cataluña e Islas Baleares, Consejo de la Juventud de España, Federación Estatal de Gays, Lesbianas y Transexuales).

\section{Discusión}

El estudio revela la escasa cobertura mediática de las campañas de prevención del $\mathrm{VIH}$, con mayor prevalencia del género informativo y el infra-uso del código icónico. La principal limitación del trabajo es que limita el análisis a los medios escritos, por lo que sería necesario estudiar también la difusión de las campañas en medios radiofónicos y de televisión. 
Los resultados revelan que las noticias de prensa se concentran en las fechas próximas a la celebración del Día Mundial del SIDA o Día del Orgullo Gay, sin mantener la cobertura a medio o largo plazo, lo que confirma los resultados de una investigación reciente sobre medios escritos nacionales (Terrón Blanco, 2011). Tomando como punto de partida la coste-efectividad de los medios de comunicación en la transmisión de mensajes preventivos del VIH (Arya, Behfoloruz y Viswanath, 2009; Hogan et al, 2005; Myhre y Flora, 2000), una línea estratégica sería intensificar el impacto de las campañas de prevención en la prensa escrita.

La visibilidad de las fuentes político-técnicas en las noticias sobre campañas preventivas del $\mathrm{VIH}$, refuerza la validez de los mensajes y avala la confianza de las audiencias en la prensa como agente institucional (Zhao et al, 2010; Feijoo Agesta, 1989). Por otra parte, los datos epidemiológicos, frecuentes en los mensajes periodísticos sobre VIH (Casabona, 2009), se configuran como elementos persuasivos eficientes para influir en las intenciones y actitudes de la población (Cappola y Camus, 2007).

Sin embargo, la prensa no refleja los debates sociales sobre la problemática de la prevención del VIH. No se recogen opiniones de pacientes, población general o de las poblaciones diana de las campañas. Los únicos dos posicionamientos emergentes en el seno de la sociedad civil confirman la sexualidad como una temática controvertida, destacando la necesidad de evitar los discursos ideológicos sobre la homosexualidad o la relación entre ETS y embarazos no deseados.

En general, el carácter de las noticias de prensa es meramente informativo, coherente con las conclusiones de la bibliografía actual (Terrón Blanco, 2011). El hecho de que la prensa informe pero no explique los eventos y cuestiones científicas, puede conllevar que la comprensión de los mensajes preventivos no vaya asociada con un adecuado impacto conductual (Snyder y Hamilton, 2002; Tambashe et al, 2003). En este sentido, el tipo de mensajes preventivos que se lanzan, así como la población diana a la que se dirigen, son aspectos fundamentales a tener en cuenta al difundir estrategias de prevención del VIH.

En nuestro estudio, las campañas con mayor difusión contienen mensajes de concienciación y se dirigen a la población general, lo que tiene una importante utilidad para reducir el estigma y la discriminación social (Fakalade et al, 2010), aumentar la conciencia social (Keating, Meekers y Adewuyi, 2006) y presentar los medios como una fuente de confianza (Zhao et al, 2010). Sin embargo, la bibliografía disponible recalca la importancia de difundir campañas con mensajes menos genéricos y más específicos, sobre la prueba de diagnóstico o uso del condón (Vidanapathirana et al, 2005; Agha, 2003), que, según nuestro análisis, han tenido una escasa difusión en la prensa analizada. Así mismo, la infrautilización del código icónico pone de manifiesto el escaso aprovechamiento de la comunicación mediática para llamar la atención de las audiencias. (Donohew, Palmgreen y Pugsles, 1994). 


\section{Conclusiones}

El estudio refleja la existencia de un patrón similar en la difusión de las campañas preventivas, con una escasa cobertura mediática. Se evidencia la necesidad de mayor visibilidad de los debates sociales generados en torno a las campañas preventivas, consolidando a la vez la comunicación entre las fuentes institucionales y las mediáticas. Asimismo, se requiere impulsar la investigación sobre nuevas estrategias de difusión de las campañas, que aporten una cobertura de mayor impacto y eficiencia.

\section{Referencias}

Abroms, L.C. y Maibach, E.W. (2008). The effectiveness of mass communication to change public behavior. The Annual Review of Public Health. № 29, pp. 219-234. Agha, S. (2003).

Agha, S. (2003). The impact of a mass media campaign on personal risk perception, perceived self-efficacy and on other behavioural predictors. AIDS care. Vol. $6, \mathrm{n}^{\circ} 15$, pp. 749-762.

Arya, M.; Behforouz, H.L.; Viswanath, K. (2009). African American women and HIV/ AIDS: a national call for targeted health communication strategies to address a disparity. The AIDS reader. № 19 (2), pp. 79-84.

Asociación para la Investigación de Medios de Comunicación (2011). Estudio General de medios. Resumen general. Febrero a Noviembre 2011. Disponible en http://www. aimc.es/-Datos-EGM-Resumen-General-.html. Recuperado el 1 de febrero de 2013.

Blanco, J.A. et al. (1995). La imagen del sida en la prensa española. Valladolid: Universidad de Valladolid.

Bekalu, M.A. y Eggermont, S. (2012). Advancing HIVIAIDS Combination Prevention through mass media: a review of practices in sub-Saharan Africa. Information Development. Vol. 3, n² 28, pp. 189-198.

Casabona J. (2009, 1 diciembre). El sida, ¿una epidemia secuestrada? El Periódico de Catalunya. Recuperado de http://www.elperiodico.com/es/noticias/opinion/20091201/ sida-una-epidemia-secuestrada/109469.shtml.

Coppola, V. y Camus, O. (2007). Preventing without stigmatizing: The complex stakes of information on AIDS. Patient Education and Counseling. Vol. 3, n 67, pp. 255-260.

Day, B. (2001). Campañas en los medios masivos de comunicación. Educación y comunicación ambientales para un mundo sustentable. Manual de experiencias internacionales. México: Grupo de Estudios Ambientales.

Donohew, L.; Palmgreen, P. y Pugzles, E. (1994). Attention, need for sensation and health communication campaigns. The American Behavioral Scientist. Nº 38, pp. 310-22. 
Fakolade, R.; Adebayo, S.B.; Anyanti, J. y Ankomah, A. (2010). The impact of exposure to mass media campaigns and social support on levels and trends of HIV-related stigma and discrimination in Nigeria: tools for enhancing effective HIV prevention programmes. Journal of Biosocial Science. Vol. 3, n 42, pp. 395-407.

Feijoo Agesta, M.R. (1989). Contribución al estudio de los problemas de información sanitaria: el caso singular del SIDA. Tesis doctoral inédita. Facultad de Medicina. Universidad de Zaragoza. Zaragoza.

Garabato González, S. (2003). La prevención delVIH/sida en los medios de comunicación social escritos: análisis cuantitativo de una muestra de diarios. Trabajo social y salud. $N^{\circ} 45$, pp. 139-154.

Gioda, L.; Llobet, L. (1995). El segundo diario. Temas y problemas de comunicación. Vol. 5, n³, pp. 31-47.

Hogan, D.R.; Baltussen, R.; Hayashi, C.; Lauer, J.A. y Salomon, J.A. (2005). Cost effectiveness analysis of strategies to combat HIVIAIDS in developing countries. British Medical Journal. № 331, pp. 1431-1435.

Humanes, M.L. (2003). La reconstrucción del pasado en las noticias. Anàlisi. Nº 30, pp. 39-57.

Keating, J.; Meekers, D. y Adewuyi, A. (2006). Assessing effects of a media campaign on HIVIAIDS awareness and prevention in Nigeria: results from the VISION Project. BMC public health. $\mathrm{N}^{\circ} 6$, pp. 123.

Lehmann, H. y Töppich, J. (2009). Communication of health risks: the example of HIV/ AIDS prevention. Bundesgesundheitsblatt, Gesundheitsforschung, Gesundheitsschutz. Vol. 12, n. 52, pp. 1147-1150.

Martín Hernández, R. (2009). El sida ante la opinión pública: el papel de la prensa y de lascampañas de prevención estatales en la representación social del sida en España. STIDIUM. Revista del Humanidades. № 15, pp. 237-268.

Martínez Nicolás, M. (1995) La construcción de la crisis del SIDA en la información periodística. Análisis del discurso informativo sobre SIDA en Cambio 16, Tiempo de Hoy e Interviú (1982-1992). Tesis doctoral inédita. Universidad Autónoma de Barcelona. Bellaterra.

Moore, D. (2009). HIVIAIDS prevention behaviours. Predictors of condom use among African-American college students. Journal of Creative Communications. Vol. 2, $\mathrm{n}^{\circ} 4$, pp. 87-109.

Myhre, S.L.; Flora, J.A. (2000). HIVIAIDS communication campaigns: progress and prospects. Journal of health communication. № 5 , pp. 29-45. 
Paricio-Esteban, P.; Rodríguez-Luque, C. y Rabadán-Zaragoza, M.J. (2012). Tratamiento del consumo de alcohol y su prevención en prensa española desde la perspectiva del framing: El País, El Mundo, Abc y La Razón. Revista Latina de Comunicación Social. Nº 67, pp. 322-46.

Snyder, L.B. y Hamilton, M.A. (2002). A Meta-analysis of U.S. Health Campaign Effects on Behavior: Emphasize Enforcement, Exposure, and New Information, and Beware the Secular Trend. En Hornik R (ed). Public Health Communication: Evidence for Behavior Change. London: Lawrence Erlbaum.

Tambashe, B.O.; Speizer, I.S., Amouzou, A. y Djangone, A.M. (2003). Evaluation of the PSAMAO "Roulez Protégé" mass media campaign in Burkina Faso. AIDS Education and Prevention. Vol. 1, n 15, pp. 33-48.

Terrón Blanco, J.L. (2011). El tratamiento del VIH-sida en los periódicos españoles, una investigación colaborativa. Revista de Comunicación y Salud. Vol. 1, $\mathrm{n}^{0}$ 1, pp. 4-17.

Tuñón, A. (1994). El sida, como factor noticiable, en la construcción del acontecimiento cultural en cuatro diarios de calidad: El País, La Vanguardia, Le Monde y The Times. Anàlisi. Vol. 4, nº 16, pp. 57-87.

Vidanapathirana, J.; Abramson, M.J.; Forbes, A. y Fairley, C. (2005). Mass media interventions for promoting HIV testing. Cochrane database of systematic reviews. No 3: CD004775.

Zhao, Q. et al. (2010). HIVIAIDS awareness and knowledge among secondary school students in China. World health \& population. Vol. 4, n 11, pp. 38-48. 